\section{Cortisone and Hydrocortisone in Cerebrospinal Fluid}

Axthovgh numerous measurements have been made of the concentration of adrenocortical steroids in various body fluids, particularly since the development of paper chromatographic methods, no data are available concerning cerebrospinal fluid.

Cerebrospinal fluid was obtained by lumbax puncture from patients in a neurological unit in the course of air encephalographic studies. Each sample was extracted within twenty-four hours of withdrawal by a modification of the method of Nelson and Samuels. The sample was shaken three times with 1.5 volumes of chloroform. The combined chloroform extracts were taken to dryness. The residue was dissolved in $50 \mathrm{ml}$. of 70 per cent ethanol, and washed three times with $25 \mathrm{ml}$. of hexane. The ethanolic solution was taken to dryness, and the residue dissolved in $0.1 \mathrm{ml}$. of ethanol for chromatography. Paper chromatography was carried out using the benzene-formamide system of Zaffaroni, Burton and Keutmann ${ }^{2}$, using appropriate standards. The chromatograms were run for $60 \mathrm{hr}$. Provisional identification and semi-quantitative comparison with standards were based on : (1) running properties of unknown compounds, compared with standards added to cerebrospinal fluid and extracted in a similar manner; added cortisone and hydrocortisone run more rapidly in extracts of cerebrospinal fluid than in the standard solutions in ethanol ; (2) ultra-violet absorption ${ }^{3}$ at $254 \mathrm{~m} \mu$; (3) reaction with a tetrazolium salt ${ }^{4}$ blue tetrazolium was used; (4) soda fluorescence ${ }^{5}$.

Recoveries of cortisone and hydrocortisone added to cerebrospinal fluid exceeded 75 per cent. There was no conversion of either compound to the other during extraction.

Examination of seven single samples of cerebrospinal fluid (each of $50-100 \mathrm{ml}$.) revealed in five samples doubtful traces of substances exhibiting soda fluorescence, and tentatively identified as cortisone and hydrocortisone by their running properties. As well as the substances exhibiting soda fluorescence, a spot $\left(R_{F}\right.$ value relative to cortisone $\left.=0.85\right)$ was occasionally found, detectable by ultra-violet absorption only.

Two pooled extracts, each representing $500 \mathrm{ml}$. of cerebrospinal fluid, were now run. Both showed the same pattern (see diagram). Substances provisionally identified as cortisone and hydrocortisone were found in concentrations of $0.1-0.2 \mu \mathrm{gm}$. and 0.2 $0.4 \mathrm{kgm}$. per $100 \mathrm{ml}$, respectively. Absolute identification by means of crystallization and melting-point determinations was not carried out because of the small amounts detected. For the same reason, running properties of the acetyl derivatives and the infra-red and ultra-violet absorption spectra were not investigated.

The provisional identification of cortisone in cerebrospinal fluid is of importance in view of the failure of some workers to find cortisone in normal human plasma ${ }^{1,6}$. Morris and Williams, on the other hand, identified both cortisone and hydrocortisone (in addition to other steroids) in human plasma, in the same ratio $(1: 2)$ as we have found in cerebrospinal fluid, although the concentrations were twenty-five times greater in plasma.

We should like to thank the Medical Superintendent and Dr. J. G. Toakley, of Hurstwood Park Hospital, Sussex, for their unfailing co-operation in

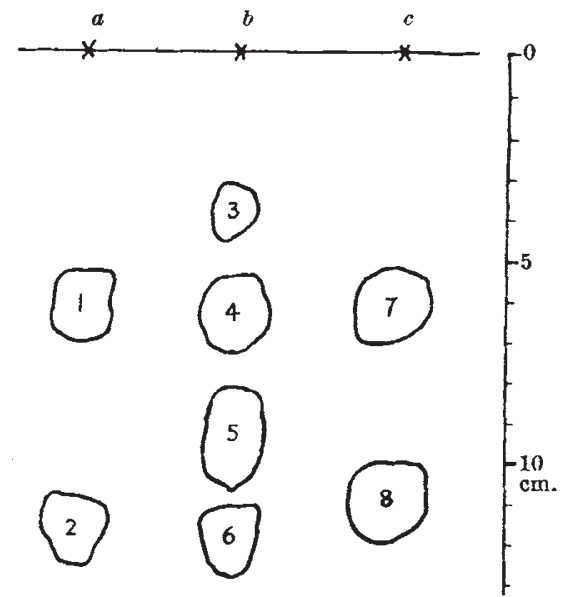

Tracing of soda fluorescence on a chromatogram run for $60 \mathrm{hr}$. at room temperature in the benzene-formamide system. (a) Extract standarda added to $50 \mathrm{nIl}$. cerebrospinal fuid;

(b) Pooled extract from 500 ml. cerebrospinal fluid : (3) yellow fluorescence, indicating trace of unidentifled substance; $R F$ value relative to cortisone, 0.3 ; (4) hydrocortisone $(1-0-2 \cdot 0 \mu \mathrm{gm}$.) ; (5) blue fluorescence, with similar running properties to substance $X$ (see ref. 5); (6) cortisone $(0 \cdot 5-i \cdot 0 \mu \mathrm{gm}$.).

(c) Standards in ethanol solution: (7) $2 \mu \mathrm{gm}$. hydrocortisone ; (8) $2 \mu \mathrm{gm}$. cortisone

providing samples of cerebrospinal fluid; Mrs. S. A. Simpson and Dr. J. F. Tait for advice; and Prof. E. C. Dodds and Prof. A. Kekwick for kindly affording facilities, and for their encouragement.

D. N. BARON

Courtauld Institute of Biochemistry,

Middlosex Hospital Medical School, London, W.1.

Dents Abexson*

Department of Medicine, Middlesex Hospital,

London, W.1. Nov. 10.

* Present address : Department of Physiology, Yale University School of Medicine, New Haven, Connecticut.

1 Nelson, D. H., and Samuels, J. T., J. Clin, Endocrinol., 12, 519 (1952). 2 Zaffaroni, A., Burton, R. B. and Keutmann, E. H., Science, 111, 6 (1950).

${ }^{3}$ Haines, W., and Drake, M. A., Fed. Proc., 9, 180 (1950).

- Burton, R. B., Zaffaroni, A., and Keutmann, E. H., J. Biol. Chem., 188, 763 (i951)

Bush, I. E., Biochem. J., 50, 370 (1952).

B Bayliss, R. I. S., and Steinbeck, A. W., Biochem. J., 54, 523 (1953). 'Morris, C. J. O. R., and Williams, D. C., Biochem. J., 54, 470 (1953).

\section{Canine Distemper Virus Complex}

Plurality of the Virus. Some cross-immunity between canine distemper and human influenza viruses $^{1}$ has been an intriguing problem for some time, and the striking immunological relationship between canine distemper and poliomyelitis has also been reported ${ }^{2}$. It was thought that canine distemper virus represented one etiological entity ${ }^{3}$ Tarpeia canis $^{4}$, which is usually referred to as Carre or Laidlaw-Dunkin virus. It has been suggested that the disease commonly referred to as 'hard pad' is produced by a different virus ${ }^{5}$. This was questioned ${ }^{6-8}$, because 'hard pad' virus in the hands of other workers was found to be immunologically indistinguishable from Carre-Laidlaw-Dunkin virus ${ }^{7,8}$, olthough cause of infection differed in the ferret ${ }^{7}$; it is noteworthy that after as few as five consecutive passages a 